\title{
AN OVERVIEW ON GREEN LOGISTICS
}

\author{
DR. NEETHU ANN GEORGIE
}

Associate Professor, Department of Management, MACFAST, Kerala, India

\begin{abstract}
Logistics decisions are considered to be strategically important for any firm and it addresses the locations, numbers, and capacities of required facilities in the transportation network and also with regard to the aggregate material flow between them. As environmental concern and sustainability started gaining magnitude, it hasn't left any ground of business and same is the case with the logistics concept. Consequently, the focus has shifted towards greening the channel and its decisional areas through an environmentally friendly logistics network design. Henceforth, in the present review, such means is referred to as "Green Logistics". Green logistics make use of a separate set of actions to achieve its objective and it enjoys a lot of recompense and also disadvantages. The paper tries to describe the operational methods focussed by green logistics and proceeds by analyzing the boons and downside of the same. Though the concept of greening has obtained wide acceptance, its relevance and practice differ with respect to economic development enjoyed by various nations and hence the success of same on developing economies is always an interesting topic for researchers and manufacturers. Hence the paper also focuses on an impression on green logistics with regard to Indian scenario.
\end{abstract}

KEYWORDS: Green Logistics, Sustainability, Logistics Activities \& Indian Scenario

Received: Apr 12, 2019; Accepted: May 02, 2019; Published: May 20, 2019; Paper Id.: IJBMRJUN20197

\section{INTRODUCTION}

Today's businesses not only face time and performance constraints but is also forced to consider the society's points of concern about the environment. The modern business sectors come up with a lot of tactics including 'sustainability' and 'go green ideologies' as they help not only in preserving the environment but also gives a competitive advantage. The 'green logistics', which is an upshot of the 'go green campaign', includes all those efforts that assist in measuring and minimizing the environmental impact of logistics activities and it also embraces a proactive design for disassembly

Logistics is the management of the surge of things between the point of origin and the point of consumption in order to meet the requirements of customers or corporations. The resources managed in logistics include physical matters like food, materials, animals, equipment, and liquids; as well as intangible items, such as time and information. Thus the logistics operations can be viewed within two major headings of product and service flows (Tuzan \& Selim, 2017). The traditional logistics seeks to organize forward distribution, that is the transport, warehousing, packaging and inventory management from the producer to the consumer but later on the environmental considerations opened up markets for recycling and disposal and led to the evolution of an entirely new sub-sector: green logistics (Byrne and Deeb 1993). The concept makes use of varied practices when compared with traditional logistics and has lot of recompense as well as disadvantages and the cram try to discuss the same 


\section{GREEN LOGISTICS OPERATIONS}

Logistics has a wide assortment of methods to guard the environment and its resources though these measures enjoy common aim, they differ in terms of range, scope, capital expenditure, and resource requirements. Logistics has five starting points, where the company can focus on implementing measures pertaining to environmental protection and resource preservation and it includes

- Layout and internal structure of the organization

- Processes used, measurement and controlling techniques

- technologies and resources

- market and product

- employees, suppliers and service providers

Irrespective of the above areas, green logistics focus on the environment, and give priority to exertions like pollution and environmental degradation, which are created due to improper logistics processes or utilization of old and environmentally unfriendly transportation. As avoiding and reducing waste is the prime motto, Green logistics focus on the recovery of inventory and the major option for recovery includes reuse, repair, recycle or remanufacturing the material before it is judged for disposal.

The organizations try to focus on different deeds to accomplish green logistics and notable among them include green purchasing, green production, sustainability in packaging and transportation, recycling, remanufacturing, reuse, etc. The activities followed by organizations to custom green logistics include the following (Buyukozkan \& Vardaroglu, 2008)

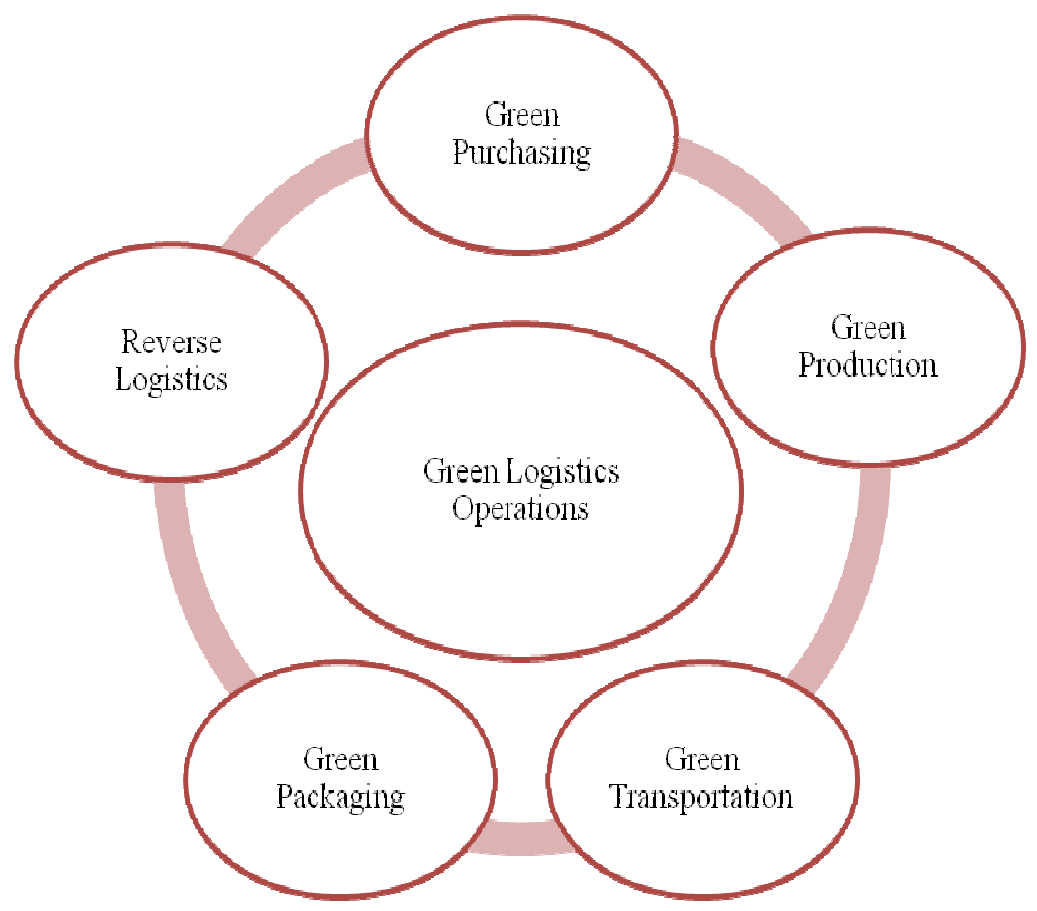

Figure 1: Operations Incorporated in Green Logistics 


\section{Green Purchasing}

Green purchasing involves purchasing products with recycled contents or those items that can be replenished or recycled and the firms making use of this strategy give preference to those materials that have fewer adverse effects on human health and environment. Thus this purchasing strategy gives the least priority to those goods and services which have negative environmental effects

\section{Green Production}

According to United Nations Program for the Environment, green production is defined as the implementation of preventative environmental management strategies which are integrated with the production process, and thus they not only improve efficiency but also results in the elimination of the risks on human health and environmental. Green production merely means the idea of producing goods and services with less waste.

\section{Green Transportation}

Distribution is the management and movement of all the materials in the value chain from the beginning to the end. Distribution does have considerable effects on the environment like the exhaust fumes of vehicles used for transportation [movement of inventory] act as one of the important causes of environmental pollution. Thus the factors affecting green distribution includes the fuel used by transporting vehicle, frequency of trips, distance to the clients and other characteristics of hauling, such as materials, shapes, and weight

The green distribution and transportation focus on using recyclable packaging or use of the reusable containers or the use of materials that are harmless to the environment in packaging and the utilization of environmental management methods during transiting.

\section{Green Packaging}

Green packaging or ecological packaging refers to the method of wrapping the product by valuing human and animal health, as well as the environment. That is the material and method chosen for packing should be environmentfriendly and this principle is followed throughout the lifecycle of the packing material. Hence use of reusable or recycled materials wholly made from natural plants will be given priority. Packages manufactured in that manner reduce the use of environment destructive materials and will also enable efficient use of space in warehouses and decrease the amount of transportation needed (Tuzun \& Selim, 2017).

\section{Reverse Logistics}

Reverse logistics is the activity of planning, implementing and controlling the efficient flow of raw materials, semi-completed or final products and the relevant information from the point of consumption to the initial stages, in a manner to ensure adding values and proper disposal.

Reverse logistics assist in minimizing the environmental impact of e-waste as it increases the number of product materials recovered from the waste stream. In this process, manufacturer systematically accepts previously shipped products or parts from the point of consumption for possible reuse, remanufacturing, recycling, or disposal and Products, components, materials, equipment, and even all the technical system can be re-used in the chain (Rahman \& Subramanian, 2012). 


\section{CONSISTENCIES AND INCONSISTENCIES OF GREEN LOGISTICS}

\section{Significance}

The "ecological concern" in logistics determines how far the corporation faces the issues of environmental protection and resource conservation while undergoing various activities in logistics. The ecological stability requires a balance between economies, environment, society, and management and green logistics can act as a conduit that can successfully convey equilibrium between these three. Thus the three main sections of green logistics include economy, society, and environment

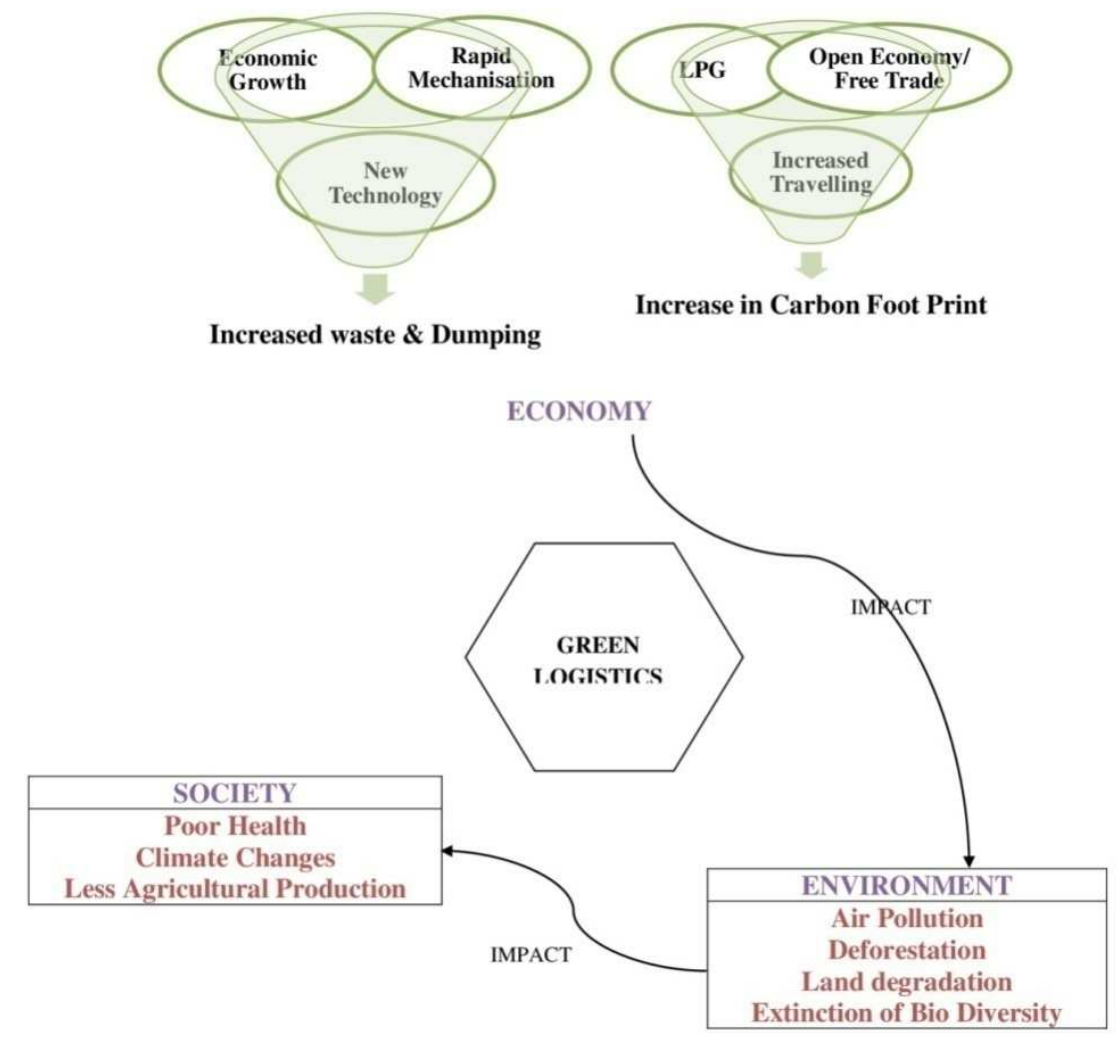

Figure 2: Green Logistics as a Boon to Society and the Environment

As business concentrates on achieving market requirement in an optimized manner, the varied strategies adopted results in the increase in carbon footprint and meanwhile their excessive expectation may also result in dumping. These two have an adverse effect in society as well as the environment and green logistics is alleged to reduce the unpleasant effects as it not only concentrates on warehousing, packaging and inventory management from the producer to the consumer but also connotes environmental consideration through the whole life-cycle of a product (Rituraj Saroha, 2014). The benefits offered by green logistics include

- Eco-Drive aims in creating awareness to the truck driver to reduce the use of fuel and also to have proper maintenance of the engine so as to reduce the exhaust emission to the environment.

- Backhaul \& Full Truck Load is related to fuel management by focusing on full space trip[ it doesn't mean an overload of weight and the load is limited to the specifications given by law]

- Eco-Packaging focusing on the selection of packaging and equipment that can be reused and recycled 
- effective utilization of all the available productive resources of organizations

- reducing waste by promoting recycling and also, the reuse of raw materials

- helps an organization to position itself, its activities and also the products as environmentally friendly

- Reduction in $\mathrm{CO}_{2}$ emissions

- Unlocking significant cost savings

- Heightened supply chain optimization

- Boosted business performance

- Enter new markets with certificates received in becoming green

- To design products that answer the environmental needs and thus create a difference

\section{Inconsistencies}

Like a coin has two sides, practise or implementation of green logistics faces few impossibilities or inconsistencies which may discourage many firms from implementing the same. The factors include

\section{Cost}

The rationale of logistics is to minimize costs especially the transport costs and these are often at dissent with environmental considerations. The cost factor may discourage firms in implementing green ideology or they may try to implement it in a cheap manner. Both will impair the implementation of green logistics strategies

\section{Flexibility}

The modern integrated supply chains provide adaptable and proficient physical distribution systems but on the other hand unmitigated production, distribution, and retailing models are consuming more space, energy and generate more emissions of hazardous gases.

\section{Time}

Most of the firms give priority to time and speed of transportation but it is achieved by using the most polluting and least energy efficient transportation mode. As time act as a vital factor, companies try to focus on flexible logistics channels so the efficiency and effectiveness will not be sacrificed. Logistics can give priority in offering door-to-door (DTD) services, coupled with just-in-time (JIT) strategies, so as to avoid the time constraint. This not only makes logistics channel effective but also increases the flexibility of industrial production systems

\section{Reliability}

The prime motto of logistics is the service reliability and its success is based upon the ability to deliver the right quantity at right time to the right place without hindering the right quality. But the least polluting modes are generally least reliable in terms of on-time delivery, lack of breakage and safety. Ships and railways have innate a repute for poor customer satisfaction, and hence logistics industry is built around air and truck, the two least environmentally-friendly modes. 


\section{Warehousing}

The organizations try to reduce the demand of warehouse by focusing on 'strategic warehouse' or 'mother warehouse' concept and for this, they rely more on the transportation system, in which the inventories are actually in transit. This contributes further to congestion and pollution.

\section{E-commerce}

The explosion of the information technology has led to new dimensions in retailing - e-commerce. However, changes in physical distribution systems by e-commerce have led to higher levels of energy consumption which may again encourage the company's in overproduction or dumping.

\section{GREEN LOGISTICS IN INDIA}

As it is well aware that developed nations give high priority to reduce Green House Gas (GHG) emissions from logistics and transportation sector, it is necessary to check the same with respect to developing countries. In India, $\mathrm{CO} 2$ emissions from the transport sector due to fossil fuel combustion has been around $4.5 \%$ compared to $1.16 \%$ in OECD countries and $1.04 \%$ in North America in the previous decade.

In India, Green logistics is only in its birth/ introductory stage and in most of the cases, it remains confined to transportation. Though it is a major sub-sector of logistics, the latter also includes facilities like warehousing, transport terminals, packaging, distribution, material handling, and even disposal. It should also be mentioned that reverse logistics sector that takes care of recovery, retrieval of parts, recycling of products and disposal of packaging waste is almost non-existent in India

For implementing green logistics in India, we need to address the issue at three tires namely public policy, business, and individual and these three interact and influence one another. Government intervention for right pricing, incentivizing, laying down regulations and enforcing them is vital for the successful development of green logistics in India

The share of rail transport has decreased radically by more than two-thirds from $89 \%$ in 1951, while the split of road transport has increased seven-fold from $10 \%$ within the same period. Restoring rail as a prime mode of transport, in particular for freight, would be essential to reduce environmental pollution as rail emissions are at least five times lesser than road emissions. Although Indian roads, despite being in bad shape, still retain a major share of transportation as they alone can provide door-to-door delivery. Hence green logistics practitioners focus on providing intermodal transport with roads providing only the last-mile delivery.

Presently many cities in India witness the replacement of fossil fuel based technology with bio-fuel based one or even with alternatives like CNG, hybrid, battery-operated vehicles and equipment and these act as a good example of green transportation. Thus it can be stated that India is witnessing many growths in green transportation and in addition to this most of the places are giving priority to green packaging as the state and central government are trying to create necessary regulations for same. This shows a positive indication and the coming years may witness the same vigor in other green logistics operations. 


\section{CONCLUSIONS}

In this competitive world, where companies try to formulate sustainable strategies to thrive in the market, green logistics procedures which aim at realizing business strategies in an environmentally-friendly manner come forward as an important face that will provide a competitive advantage for businesses. As the strategy enjoys a lot of recompenses, and as it gives primary consideration to environment and sustainability, government irrespective of the economic conditions should formulate clear cut system and methodologies for implementing the same as it is sure that logistics, though oblivious to most of the people, is a primary activity of any firm and has direct influence on society as well as environment.

As factors like congestion, land take, environmental degradation are becoming a major concern in the modern day, the legislators should bring in keen steps to make all deeds in the nation as environment-friendly ones. In such a scenario, green logistics can be a winning and flourishing operational strategy that can bring a match and balance between environmental considerations and profit

\section{REFERENCES}

1. Alzaman, C. (2014). Green supply chain modelling: Literature review. International Journal of Business Performance Supply Chain Model, 6(1), 16-39.

2. Byrne P. and Deeb A. (1993) “Logistics must meet the 'green' challenge”, Transportation and Distribution,2, 33-35

3. Jayaraman, V., R. A. Patterson, E. Rolland. 2003. The design of reverse distribution networks: Models and solution procedures. European Journal of Operational Research 150(1): 128-14

4. Lee, D. H, M. Dong, W. Bian. 2010. The design of sustainable logistics network under uncertainty. International Journal of Production Economics 128(1): 159-166.

5. Linton, J.D., Klassen, R. \& Jayaraman, V. (2007). Sustainable supply chain: An introduction. Journal of Operations Management, 25, 1075-1082.

6. Rodrigue, J. P., Slack, B., \& Comtois, C. (2001). Green logistics (the paradoxes of). The Handbook of Logistics and SupplyChain Management

7. Saroha, Rituraj (2014), 'Green Logistics \& its Significance in Modern Day Systems', International Review of Applied Engineering Research, 4(1), 89-92

8. Shirur, S., \& Torgal, S. Recent trends of Information Technology in Logistics and Supply Chain Management of Indian Agriculture Industry.

9. Shams Rahman, Shams and Subramanian, Nachiappan (2012), 'Factors for implementing end-of-life computer recycling operations in reverse supply chains', International Journal of Production Economics, 140(1), 239-248

10. Tuzan, Sevgi and Selim, Yavuz (2017), 'Green Logistics for Sustainability', Int. Journal of Management Economics and Business'.13 (3), 603-614 
